\title{
PRESENÇA DE BPV-2 EM TUMOR CUTÂNEO E LEITE DE CABRA (CAPRA HIRCUS)
}

\author{
N. E. PONTES ${ }^{1}$, E. TIBÚRCIO Jr' ${ }^{2}$, M. A. S. ANDRADE ${ }^{1}$, M. A. R. $\operatorname{SILVA}^{3}$ e A. C. \\ FREITAS $^{1}$
}

${ }^{1}$ Universidade Federal de Pernambuco, Centro de Ciências Biológicas, Departamento de Genética

${ }^{2}$ Universidade Federal de Pernambuco, Centro de Ciências Biológicas, Departamento de Inovação Terapêutica

${ }^{3}$ Instituto Federal da Paraíba, Campus Patos-PB

E-mail para contato: acf_ufpe@yahoo.com.br

\begin{abstract}
RESUMO - O nosso estudo buscou investigar a presença do BPV-2 em amostras de cabras, tentando verificar a existência de infecção cruzada do vírus com outras espécies animais além do hospedeiro natural (bovino). Foram obtidas amostras de lesões cutâneas e leite, controles positivos e negativos para o Papilomavírus tipo 2. A detecção do DNA viral foi realizada utilizando a técnica de PCR com primers específicos para o BPV-2. Obtivemos como resultado a positividade das amostras para o tipo viral demonstrando que o vírus alcançou um outro hospedeiro diferente do bovino. Como conclusão, o BPV-2 foi identificado pela primeira vez em amostras de cabra (Capra hircus), tanto em tecido epitelial como não-epitelial.
\end{abstract}

Palavras-chave: BPV. Cabra. Infecção cruzada. Detecção. Virus.

ABSTRACT - Our study aimed to investigate the presence of BPV-2 in goats samples, trying to verify the existence of cross-infection of the virus with other animal species besides the natural (bovine) host. Samples of cutaneous lesions and milk, positive and negative controls for Papillomavirus type two we obtained. Viral DNA detection we performed using the PCR technique with BPV-2 specific primers. We obtained as a result the positivity of the samples for the viral type demonstrating that the virus reached another host different from the bovine one. In conclusion, BPV-2 we identified first in goats samples (Capra hircus) in both epithelial and non-epithelial tissues.

Keywords: BPV. Goats. Cross infection. Detection. Virus.

\section{INTRODUÇÃ̃O}

Os Papilomavírus bovinos são vírus de DNA, dupla fita, com genoma de aproximadamente $8000 \mathrm{pb}$. Existem 14 tipos de BPV (BPV-1 a 14) descritos na literatura (Lunardi et al., 2013; Munday et al., 2015), além de diversos prováveis novos tipos e subtipos (Freitas et al., 2011; Silva et al., 2011; Silva et al., 2012; Batista et al., 2013). Embora os Papilomavírus sejam descritos classicamente como epiteliotrópicos, a atividade destes vírus já foi verificada em sangue e sêmen de bovinos (Roperto et al., 
2008; Carvalho \& Stocco, 2009; Silva et al., 2013). A alta incidência de BPV já foi verificada em doses de sêmen congelado comercial de bovinos (Silva et al., 2011), assim como a atividade biológica desses vírus em sêmen e sangue (Roperto et al, 2011; Silva et al.,2013a). Além disso, a sua presença já foi encontrada em fluidos como plasma sanguíneo, leite e colostro (Dos Santos et al., 1998; Freitas et al., 2003; Freitas et al., 2007) e no trato reprodutivo em sítios como oócitos, ovário, útero, células do cúmulus, fluidos uterinos, placenta e líquido amniótico (Freitas et al., 2007).

O BPV infecta bovinos mas também infecta parentes próximos como búfalos e girafas causando fibropapilomas e lesões da bexiga; e animais mais distantes como, antas, cavalos, antílope africano e zebras; e causam sarcóides e fibrosarcomas quando inoculados em roedores (Freitas et al., 2011). Segundo Bocaneti et al. (2013), quatro tipos de BPV foram descritos (BPV-1, -2, -5 e -13) como infectantes de outras espécies.

De acordo com Munday et al. (2015), os sarcóides felinos são neoplasias mesenquimais raras de gatos domésticos e exóticos. Estudos anteriores detectaram consistentemente sequências de DNA curtas de um papilomavírus (PV), papilomavírus associado a sarcoídeos felinos (FeSarPV), nessas neoplasias. A sequência FeSarPV nunca foi detectada em amostras não sarcóides de gatos, mas foi amplificada a partir da pele de gado, sugerindo que os sarcóides felinos são causados por infecção de espécies cruzadas por um vírus do papiloma bovino (BPV-14).

A cabra (Capra hircus) possui um Papilomavírus específico (ChPV-1) com aproximadamente $7600 \mathrm{pb}$ e baseado em análise filogenética baseado em alinhamento concatenado com as ORFs E1, E2, L1 e L2 de ChPV-1 e de outros 54 tipos de Papilomavírus humano (HPV) e bovino (BPV), formou clusters com os BPV-3, -4 e -6 (Doorslaer et al., 2006).

Uma biblioteca genômica de cabra foi rastreada por hibridação Southern blot com uma sonda de DNA de BPV 5, verificou-se um clone recombinante que se hibridou com o genoma do BPV-5 (sendo um único subfragmento de 1,0 kb dentro da estrutura da ORF E1 do BPV-5). Além disso hibridou com os genomas do Papilomavírus humano (HPV-5 e HPV-8) e dois Papilomavírus murino, mas não com outros PVs (Kulski e Ward et al., 2000).

Até o momento não tinha sido relatado na literatura a detecção da presença de BPV em amostras clínicas de cabra. O nosso estudo buscou investigar a presença do BPV-2 em amostras de cabras (lesões cutâneas e leite), tentando verificar a existência de infecção cruzada do vírus com outras espécies animais.

\section{MATERIAIS E MÉTODOS}

Amostras obtidas: Foram obtidas duas amostras de lesão cutânea de cabra, e uma amostra de leite de cabra, oriundas do município de Sertânia-PE, Estação Experimental de Sertânia do Instituto Agronômico de Pernambuco - IPA, local de permanência dos animais. A pesquisa foi desenvolvida no Laboratório de Estudos Moleculares e Terapia Experimental (LEMTE-UFPE). Para controle positivos e negativos foram obtidas uma amostra de DNA positiva para o Papilomavírus tipo 2 (BPV-2), e outra negativa para o BPV-2, de lesões cutâneas de fêmeas bovinas.

Extração de DNA: O DNA total foi extraído por kit comercial (Wizard® Genomic DNA Purificação; Promega, Wisconsin, EUA) e armazenados a $-20^{\circ} \mathrm{C}$ até a análise. O DNA extraído foi quantificado com o auxílio do equipamento NanoVue (GE, Alemanha). 
Reação de PCR: Cerca de 100ng de DNA foram utilizados para a análise por PCR utilizando o kit de reagentes Master mix (Promega, USA). Para a detecção de sequências de DNA paras os BPVs foram utilizados primers consenso FAP 59/64 de acordo com as condições descritas em Carvalho et al. (2012). Após a detecção do BPV, as amostras positivas foram submetidas à tipificação com primers específicos para o tipo viral BPV2 (Silva, 2012). Os produtos de amplificação $(10 \mu \mathrm{L})$ foram submetidos à eletroforese em gel de agarose a $2 \%$ em tampão TAE, corados com brometo de etídio, visualizados sob luz ultravioleta e foto documentado.

\section{RESULTADOS E DISCUSSÃO}

O BPV-2 foi encontrado em uma amostra de lesão, e uma amostra de leite de cabra. Todas de um mesmo animal, enquanto a amostra de lesão do outro animal foi negativa para o tipo investigado (Figura 1). Os controles utilizados foram amostras de bovinos, sendo uma amostra de lesão positiva e outra negativa para o BPV-2, mostrando que não houve a presença de falso-positivo e nem de falso-negativo na PCR. O controle branco (sem DNA) também foi negativo como esperado, não havendo contaminação cruzada.

Foi demonstrada a presença de BPV-2 nas amostras (leite e lesão) de cabra investigada, com tamanho do fragmento de $164 \mathrm{pb}$ esperado. Uma amostra do outro animal (lesão) foi negativa para o BPV-2. As amostras controles utilizadas mostraram resultados coerentes. Nossos resultados corroboram com outros trabalhos que encontraram BPV-2 em espécies animais diferentes dos bovinos. Bogaert et al. (2010) também detectaram a presença de BPV-1 e BPV-2 em amostras de sarcóides equinos, por meio da técnica de PCR em tempo real. Bogaert et al. (2011) demonstraram a presença destes vírus em amostras de tumores de pele de equinos. Silva et al., 2014 demonstraram a presença do DNA viral em amostras de sangue e de sêmen equinos.

Como relatado por Van Dyk et al. (2009), que detectou a presença do BPV-1 e BPV-2 em amostras de tumores sarcóides, de pele e de sangue de zebras por PCR em tempo real e RFLP (somente em tumores sarcóides). Sugere-se que o sangue pode atuar como um sítio de propagação do vírus dentro do animal, e assim atingir outros tecidos não-epiteliais, como leite, sêmen, tecidos reprodutivos e até mesmo sistema digestório do animal.

A presença dos tipos virais BPV-1 e BPV-2 também foi demonstrada em lesões cutâneas de girafas e antílope da África, como também partículas esféricas de Papilomavírus e capsômeros distintos, foram visualizadas por microscopia eletrônica. Os núcleos das células infectadas apresentaram aglomerados irregulares de cromatina condensada (Van Dyk et al., 2011). Pangty et al. (2010), demonstraram a presença dos BPV-1 e BPV-2 em amostras de bovinos e búfalos por meio da técnica de PCR em tempo real. O BPV foi encontrado também em felinos (Munday et al. 2015). Nestes, o BPV-14 causa o sarcóide felino.

Figura 1 - Detecção de Papilomavírus tipo 2 (BPV-2) em amostras de cabras e fêmeas bovinas. Amplificação de DNA em gel de agarose utilizando primers específicos para o BPV-2, mostrando fragmento esperado de $216 \mathrm{pb}$. M1Kb: Marcador Molecular $1 \mathrm{~Kb}, \mathrm{C}-$ : controle negativo de reação (sem template), LEIC1: Amostra 1 de Leite de cabra, LESC1: Amostra 1 de Lesão cutânea de cabra, Amostra 2 de Lesão cutânea de cabra, 062B: amostra de lesão cutânea bovina negativa para o BPV-2, 002B: amostra de lesão cutânea bovina positiva para o BPV-2. 


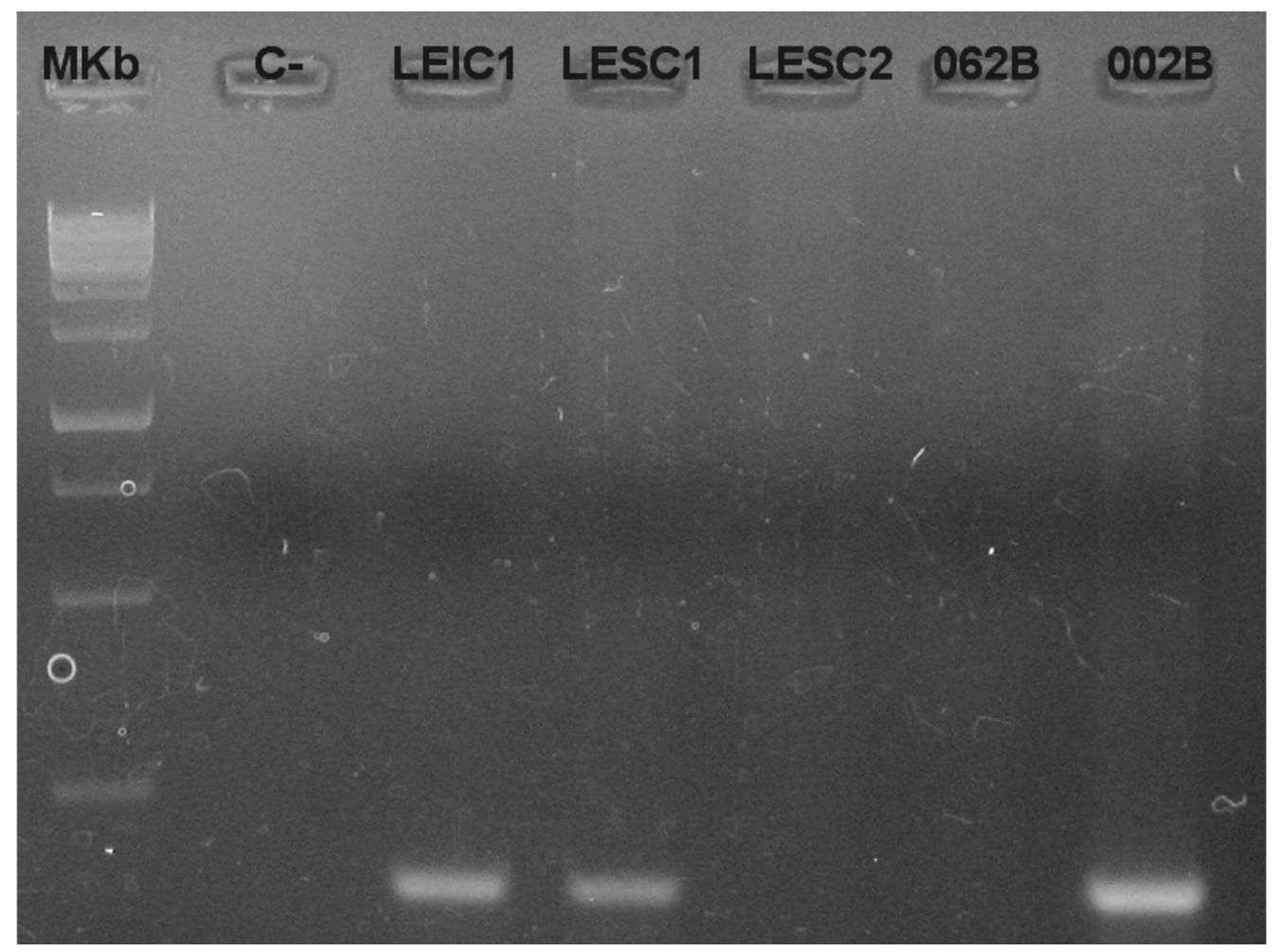

\section{CONCLUSÃO}

É possível concluir que foi identificado o BPV-2 em amostras de espécie diferente ao seu hospedeiro natural (bovinos), sendo o primeiro estudo que demonstrou a presença de Papilomavírus bovino na espécie Capra hircus, tanto em tecido epitelial como em tecido não-epitelial.

\section{REFERÊNCIAS}

Batista, M.V.A.; Silva, M.A.R.; Pontes, N.E.; Reis, M.C.; Corteggio, A.; Castro, R.S.; Borzacchiello, G.; Balbino, V.Q.; Freitas, A.C. Molecular epidemiology of bovine papillomatosis and the identification of a putative new virus type in Brazilian cattle. The Veterinary Journal, v. 197, p. 368-373, 2013.

Bogaert, L.; Martens, A.; Kast, W.M.; Van-Marck, E.; De Cock, H. Bovine papillomavirus DNA can be detected in keratinocytes from equine sarcoids. Vet. Microbiol., v. 146, p. 269-275, 2010.

Bogaert, L.; Van Heerden, M.; De Cock, H.E.V.; Martens, A.; Chiers, K. Molecular and immunohistochemical distinction of equine sarcoid from schwannoma. Vet. Pathol., v. 10, p. 1177, 2011.

Carvalho, R.F.; Stocco, R.C. Simultaneous presence of bovine papillomavirus in blood and in short-term lymphocyte cultures from dairy cattle in Pernambuco, Brazil. Genet. Mol. Res., v. 8, p. 1474-1480, 2009. 
Carvalho, C.C.R.; Batista, M.V.A.; Silva, M.A.R.; Balbino, V.Q.; Freitas, A.C. Detection of bovine papillomavirus types, co-infection and new BPV11 subtype in cattle. Transboundary and Emerging Diseases, v. 59, p. 441-447, 2012.

Freitas, A.C.; Silva, M.A.R.; Jesus, A.L.S.; Mariz, F.C.; Cordeiro, M.N.; Albuquerque, B.M.F.; Batista, M.V.A. Recent insights into Bovine papillomavirus. Afr. J. Microbiol. Res. v. 55, p. 6004-6012, 2011.

Freitas, A.C.; Silva, M.A.R.; Carvalho, C.C.R.; Birgel-Jr, E.H.; Santos, J.F.; Beçak, W.; Stocco dos Santos, R.C. Papillomavirus DNA detection in non-epithelial tissues: a discussion about bovine papillomavirus. In: Communicating Current Research and Educational Topics and Trends in Applied Microbiology, pp. 697-704, 2007. Edited by A. Mendez-Villas, Formatex: Badajos.

Freitas, A.C.; Carvalho, C.; Brunner, O.; Birgel Jr, E.H.; Libera, A.M.D.; Benesi, F.J.; Beçak, W.; Stocco dos Santos, R.C. Viral DNA sequences in peripheral blood and vertical transmission of the vírus: a discussion about BPV-1. Braz. J. Microbiol. v. 34, p. 76-78, 2003.

Lunardi, M.; Alfieri, A.A.; Otonel, R.A.; de Alcantara, B.K.; Rodrigues, W.B.; de Miranda, A.B.; Alfieri, A.F. Genomic characterization of a novel bovine papillomavirus member of the Deltapapillomavirus genus. Veterinary Microbiology, v. 162, n. 1, p. 207$213,2013$.

Munday J.S.; Thomson N.; Dunowska M.; Knight C.G.; Laurie, R.E.; Hills, S. Genomic characterisation of the feline sarcoid-associated papillomavirus and proposed classification as Bos taurus papillomavirus type 14. Veterinary Microbiology, v. 177, p. 289-295, 2015.

Pangty, K.; Singh, S.; Goswami, R.; Saikumar, G.; Somvanshi, R. Detection of BPV-1 and -2 and Quantification of BPV-1 by Real-Time PCR in Cutaneous Warts in Cattle and Buffaloes. Transboundary and Emerging Diseases, v. 57, p. 185-196, 2010.

Roperto, S.; Comazzi, S.; Paolini, F.; Borzacchiello, G.; Esposito, I.; Russo, V.; Urraro, C.; Venuti, A.; Roperto, F. Peripheral blood mononuclear cells are additional sites of productive infection of bovine papillomavirus type 2. J. Gen. Virol., v. 92, p. 1787-1794, 2011.

Roperto, S.; Paolini, F.; Urraro, C.; Russo, V.; Borzacchiello, G.; Raso, C.; Rizzo, C.; Roperto, F.; Venuti, A. Detection of bovine papillomavirus type 2 in peripheral blood of cattle urinary bladder tumours: possible biological role. J. Gen. Virol., v. 89, p. 30273033, 2008.

Silva, M.A.R.; Silva, K.M.G.; Jesus, A.L.S.; Barros, L.O.; Corteggio, A.; Altamura, G.; Borzacchiello, G.; Freitas, A.C. The Presence and Gene Expression of Bovine Papillomavirus in the Peripheral Blood and Semen of Healthy Horses. Transboundary and Emerging Diseases, v. 61, n.4, p. 329-333, 2014.

Silva, M.A.R.; Carvalho, C.C.R.; Coutinho, L.C.A.; Reis, M.C.; de Aragão Batista, M.V.; de Castro, R.S.; dos Anjos, F.B.R.; de Freitas, A.C. Co-infection of Bovine Papillomavirus and Feline-Associated Papillomavirus in bovine cutaneous warts. Transboundary and Emerging Diseases, v. 59, p. 539-543, 2012. 
Silva, M.A.R.; Pontes, N.E.; Da Silva, K.M.G.; Guerra, M.M.P.; Freitas, A.C. Detection of bovine papillomavirus type 2 DNA in commercial frozen semen of bulls (Bos taurus). Animal Reproduction Science, v. 129, p.146-151, 2011.

Van Dyk, E., Bosman A.M., VanWilpe, E.,Williams J.H., Bengis R.G., Van Heerden J., Venter E.H., 2011. Detection and characterisation of papillomavirus in skin lesions of giraffe and sable antelope in South Africa. Journal of the South African Veterinary Association , v. 82, n. 2, p. 80-85, 2011.

Van Dyk, E.; Oosthuizen, M.C.; Bosman, A-M; Nel, P.J.; Zimmerman, D.; Venter E.H. Detection of bovine papillomavirus DNA in sarcoid-affected and healthy free-roaming zebra (Equus zebra) populations in South Africa. Journal of Virological Methods, v.158, p. 141-151, 2009.

\section{AGRADECIMENTOS}

Agradeço a FACEPE pelo apoio financeiro.

Ao IPA-PE por ceder as amostras para a pesquisa.

A UFPE, PPGG por todo apoio acadêmico.

Ao LEMTE-UFPE e todos meus colegas do laboratório.

Ao GEMAP grupo de pesquisa ao qual faço parte. 